\title{
A MUDANÇA DAS POLICY NA COLÔMBIA: DAS POLÍTICAS ASSISTENCIAIS DE SAN AO DESENVOLVIMENTO RURAL PARA A AGRICULTURA FAMILIAR
}

\section{THE POLITICAL TURN IN COLOMBIA: FROM ASSISTENTIALIST POLICIES IN FSN TOWARDS RURAL DEVELOPMENT FOR FAMILY FARMING}

\author{
EL GIRO DE LAS POLICY EN COLOMBIA: DE LAS POLÍTICAS \\ ASISTENCIALES EN SAN HACIA EL DESARROLLO RURAL PARA LA \\ AGRICULTURA FAMILIAR
}

\author{
Patricia Elena Giraldo Calderón ${ }^{1}$ \\ https://orcid.org/0000-0003-3400-7086 \\ María Rocío Bedoya Bedoya ${ }^{2}$ \\ https://orcid.org/0000-0003-0219-6206
}

Submissão: 10/11/2019 / Aceite: 06/01/2020.

\begin{abstract}
RESUMO
Este artigo visa analisar as transformações das políticas de segurança alimentar e nutricional -SAN- na Colômbia entre os anos 2007 e 2017. Para atingir esse objetivo, o artigo parte de uma perspectiva histórica e geográfica, para delinear as diferentes discussões teóricas sobre agricultura familiar. Seguidamente, o caso da Colômbia é sistematizado para explicar a transformação das políticas públicas de segurança alimentar e de desenvolvimento rural e a inclusão de uma categoria emergente: a Agricultura Camponesa, Familiar e Comunitária - ACFC, institucionalizada desta forma na Colômbia. Como conclusão, pode-se afirmar que essa transformação está associada, em grande parte, ao reconhecimento mundial do papel da agricultura familiar na provisão de alimentos, bem como da sua importância na sustentabilidade ambiental e nas mudanças climáticas, para modificar "o velho paradigma" da produção de alimentos.
\end{abstract}

Palavras-chave: SAN; desenvolvimento rural; agricultura familiar; políticas públicas; Colômbia.

\begin{abstract}
In this article it is proposed to analyze the transformations of the food and nutrition security policies -SAN- of Colombia between 2007 and 2017. To respond to this objective, this work assumes a historical and geographical perspective to delineate the different theoretical considerations on the family agriculture. Subsequently, the case of Colombia is systematized to explain the transformation of food security and rural development policies and the inclusion of an emerging category: Farming, Family and Community -ACFC-, thus institutionalized in Colombia. In conclusion, it can be affirmed that this transformation is associated, the global recognition of the role of family farming in the provision of food as well as its importance in environmental sustainability by modifying the old paradigm of food production and in this way Contribute to climate change.
\end{abstract}

Keywords: FSN, rural development, family farming, policy, Colombia.

\section{RESUMEN}

En este artículo se propone analizar las transformaciones de las políticas de seguridad alimentaria y nutricional -SAN- de Colombia entre los años 2007 y 2017. Para responder a este objetivo, este trabajo asume una perspectiva histórica y geográfica para delinear las diferentes discusiones teóricas sobre agricultura familiar. Posterior a ello, el caso de Colombia es sistematizado para explicar la transformación de las políticas de seguridad alimentaria y de desarrollo rural y la inclusión de una categoría emergente: Agricultura Campesina, Familiar y Comunitaria -ACFC-, así institucionalizada en Colombia. Como conclusión, se puede afirmar que esta transformación está asociada, al reconocimiento mundial del papel de la agricultura familiar en la provisión

\footnotetext{
${ }^{1}$ Mestra em Desenvolvimento Rural pela Universidade Federal do Rio Grande do Sul (UFRGS). Docente universitária e pesquisadora. E-mail: pgiraldo.cal@gmail.com

${ }^{2}$ Doutora em governo e administração pública pela Universidade Complutense de Madri - Espanha. Professora Associada na Universidad de Antioquia - Colômbia. E-mail: maria.bedoya@udea.edu.co
} 
de alimentos, así como, su importancia en la sostenibilidad ambiental al modificar el viejo paradigma de la producción de alimentos y por esta vía contribuir al cambio climático.

Palabras-chave: SAN; desarrollo rural; agricultura familiar; políticas públicas; Colombia.

\section{INTRODUÇÃO}

O cenário político internacional da agricultura mudou drasticamente a partir do ano 2008. A crise do sistema alimentar, o preço do petróleo e os fortes incrementos nos preços dos insumos agropecuários, criaram as condições para uma mudança significativa nos padrões da produção de alimentos. Nesse ínterim, as políticas de segurança alimentar eram atualizadas em vários países da América Latina, e o Brasil ganhava um maior posicionamento como exportador de modelos bem-sucedidos para articular o combate à fome, o aumento da renda e as políticas para agricultura familiar.

Na Colômbia, embora fosse formulada uma política pública em Segurança Alimentar e Nutricional -SAN- em 2007 (COLOMBIA. DNP, 2007), seu foco principal esteve na assistência social, isto é, garantir que as pessoas não morressem de fome pela via de fornecer cestas de alimentos ou, no caso que a desnutrição fosse crônica, garantir centros de recuperação nutricional com atendimento integral para crianças. Nessa política era reconhecida a importância das políticas de desenvolvimento rural na produção de alimentos, ainda assim, o papel proativo que deveria exercer o Ministério de Agricultura e Desenvolvimento Rural -MADR ${ }^{3}$ - nunca aconteceu, motivo pelo qual, essas ações governamentais tiveram um atraso de mais de 5 anos no país.

Essa situação começa a ser modificada em 2012 com a criação do Plano Nacional de SAN (2012-2019), ganhando uma legitimidade a partir do ano 2014, graças à comemoração do Ano Internacional da Agricultura Familiar. Desta forma mobiliza sociedade e às instituições em três aspectos: a) elaboração de documentos de orientação institucional para a construção de políticas públicas nos territórios, b) mobilização social em torno da problemática e, c) engajamento do MADR no desenho e execução de políticas que articulem desenvolvimento rural e SAN, conseguindo assim, a visibilização da Agricultura Familiar neste processo.

\footnotetext{
${ }^{3}$ Em diante MADR.
} 
A definição que há da agricultura familiar é mais ou menos recente no país e portanto o Censo de 2014 não contabilizou a população rural sob este conceito, ainda assim, vários autores têm apresentado algumas estatísticas e vêm constituindo um referencial. Por exemplo, segundo Osorio e Collazos (2016) no Tercero Censo Nacional Agropecuario de 2014, 82\% das lavouras representam o 6,3\% da área rural dispersa, representando 7 milhões 115 mil hectares e 2,7 milhões de produtores e destes, 23,2\% são mulheres. Num estudo prévio, (MACHADO; BOTELLO, 2013, p. 10) foi identificado, a partir da Gran Encuesta Integrada de Hogares -GEIH-, que entre 1996 e 2011, 1.392 .568 eram agricultores familiares especializados em atividades agrícolas e 7.047 eram pluriativos.

No contexto atual, essa articulação AF/desenvolvimento rural/SAN, cobra uma maior importância e contribui para o pós-conflito, fazendo parte dos acordos finais para a terminação do conflito armado interno ${ }^{4}$, e, portanto, com o compromisso assumido pelo governo colombiano para criar políticas públicas que façam a união entre desenvolvimento econômico e desenvolvimento social. Para efeitos deste artigo, o desenvolvimento rural é entendido como o processo por meio do qual é possível melhorar as condições de vida da população rural, sejam de emprego, assistência social, capacidade produtiva, entre outras (PARAGUAY. INSTITUTO NACIONAL DE DESARROLLO RURAL Y DE LA TIERRA, 2004). Além disso, essa melhoria parte do reconhecimento do território e de uma visão de desenvolvimento abrangente enquanto à inclusão das pessoas, procurar a equidade e a sustentabilidade ambiental (ESCOBAR, 2012).

Por sua vez, existem extensas discussões em torno da categoria agricultura familiar. Neste trabalho essa categoria é entendida como um sistema de produção e um modo de vida, praticado pela diversidade de moradores rurais (indígenas, afrodescendentes e camponeses), que desenvolvem diversas atividades produtivas, de transformação e de comercialização a través da participação da família e com um forte vínculo com o território. Em geral, caracterizam-se pela pluriatividade e multifuncionalidade, além da capacidade de desenvolver muito mais que atividades produtivas agrícolas, como fortalecer o tecido social e proteger o

\footnotetext{
${ }^{4}$ O Conflito Armado Interno no país iniciou com uma guerra civil em 1948, que logo transformou-se com a criação das guerrilhas em 1956. A existência deste conflito bélico foi reconhecida pelo Estado em 2011 com a Lei 1448, e em 2016 o governo assina um acordo de paz com um dos grupos armados mais representativos. A título de exemplo, e segundo o relatório do CNMH (2016), um município de pequeno porte e fortemente atingido pelos atores em disputa padeceu quase três mil desaparecimentos forçados, dez massacres e em torno de 34 mil pessoas deslocadas forçadamente num período curto de tempo (1997-2007) (p. 18-19).
} 
patrimônio natural e cultural dos espaços rurais (ACEVEDO-OSORIO; SUÁREZ; WAEGNER, 2019; COLLAZOS, 2016).

A segurança alimentar constitui " [...] el derecho de toda persona a tener acceso a alimentos sanos y nutritivos, en consonancia con el derecho a una alimentación apropiada y con el derecho fundamental de toda persona a no padecer hambre" (AECID; PROYECTO FOOD FACILITY HONDURAS, 2011, p.2). O conceito envolve 4 dimensões: 1) disponibilidade, seja por produção, importação, estocagem ou AID; 2) estabilidade, de forma a contribuir para conter riscos de insegurança alimentar; 3) acesso e controle, tanto aos meios de produção, quanto aos mercados; e 4) consumo e aproveitamento biológico, em geral, referido às preferências alimentares da população baseadas na cultura. (AECID; PROYECTO FOOD FACILITY HONDURAS, 2011).

Por fim, este artigo tem por objetivo, analisar as transformações das políticas de segurança alimentar e nutricional -SAN- na Colômbia, entre os anos 2007 e 2017. Metodologicamente, foi realizada uma revisão bibliográfica, em conjunto com algumas entrevistas aos principais atores do setor, e também foram consideradas estatísticas do setor público. A modo de hipótese, as políticas desenhadas para o primeiro decênio do novo milênio visavam consolidar uma assistência social de combate à fome, em quanto existia uma perspectiva emergente desde 2012 que integrava segurança alimentar e desenvolvimento rural com a agricultura familiar como categoria dobradiça que liga a garantia do direito humano a uma alimentação adequada e as possibilita. O documento estrutura-se em duas seções. $\mathrm{Na}$ primeira seção, serão abordadas as discussões teóricas em agricultura familiar, camponesa e pequena produção. Na segunda seção, será descrito como o conceito de agricultura familiar é inserido na Colômbia para articular desenvolvimento rural e segurança alimentar. Por fim, apresentam-se algumas conclusões.

\section{O PAPEL DA AGRICULTURA FAMILIAR: O DEBATE INTERNACIONAL}

Um dos antecedentes desta discussão está presente no artigo "Agricultura familiar e campesinato: rupturas e continuidade", da autora Maria de Nazareth Baudel Wanderley. A autora apresenta as principais posturas clássicas com relação ao camponês, entendido como sujeito tradicional adverso às transformações tecnológicas, em contraste com a agricultura familiar, eixo articulador das políticas para a modernização da agricultura e, em consequência, 
susceptível de intervenção pública. Segundo a autora, esta última concepção encontra-se arraigada a uma definição operativa das políticas agrícolas, por exemplo, à europeia como a $\mathrm{PAC}^{5}$, e depois à brasileira, como o $\mathrm{PRONAF}^{6}$, entendendo que os agricultores familiares são geridos pelo Estado mediante políticas públicas para responder às exigências das sociedades modernas e do mercado. (WANDERLEY, 2003, p. 42-44).

Posteriormente, o debate evoluiu para um novo patamar, na discussão da mercantilização da agricultura familiar. Neste debate, Long e Long (1992), como expositores desta posição, analisam os mecanismos de inserção nos mercados da agricultura familiar enquanto estes enfrentam squeezes $^{7}$ que os marginalizam e obrigam à criação de mercados alternativos. Neste contexto, as políticas têm se orientado a dar valor agregado na produção, promovendo a agroindústria e criando estratégias de dinamização de mercados locais, de um lado e, de outro, através das políticas, articulando os diferentes níveis de governo e dos programas (WILKINSON, 2008, p. 25).

A partir da pequena agricultura familiar, Chiriboga (2002), examina as consequências da abertura aos mercados internacionais e as reformas do Estado, assim como os efeitos sobre os produtores. Para este autor, a agricultura familiar dispõe de terra, tem acesso à água, produz para o mercado primordialmente, incorpora mudanças tecnológicas, faz uso das sementes melhoradas e dos agrotóxicos e, em ocasiões, faz uso de maquinarias. O principal efeito das políticas, tanto da abertura, quanto das reformas, são a perda das políticas setoriais e o detrimento das organizações que prestaram apoio aos pequenos produtores. As políticas, em tempos passados, tinham contribuído para estimular a produção de alimentos para fornecer às cidades e alguns números de exportação, como café e cacau nos pequenos produtores. Como efeito da perda deste tipo de política, aponta o autor, acontece uma concentração da produção dos produtos mais competitivos nos mercados internacionais, uma perda de culturas tradicionais (grãos básicos da dieta alimentar), crise das organizações de produtores, diversificação de fontes de ingresso e produção, entre outros.

No caso africano, Steve Wiggins (2009), examina a relação entre desenvolvimento agrícola, pobreza e segurança alimentar. $\mathrm{O}$ autor faz um questionamento da efetividade das

\footnotetext{
${ }^{5}$ Política Agrícola Comum da União Europeia

6 Programa Nacional de Fortalecimento da Agricultura Familiar

${ }^{7}$ Em um trabalho posterior Ploeg, discípulo do Long, explica que esses squeezes ou apertes gerados pelo império alimentar, constituem estratégias de extração de renda através de instrumentos como créditos, ou na mediação entre a relação entre consumidores e produtores (PLOEG, 2010).
} 
políticas de desenvolvimento agrícola na África para atingir dois objetivos simultaneamente: melhorar a produção de alimentos e apoiar o desenvolvimento dos pequenos produtores (small farmer). Para tanto, sua crítica parte de dois argumentos: de um lado, o desenvolvimento agrário não leva automaticamente à redução da pobreza nem a uma melhor nutrição; de outro lado, a falsa convicção que a segurança alimentar poderia se obter com a importação de alimentos. Em consequência, propõe uma abordagem dos pequenos produtores e sua eficiência relativa. Desta forma, o autor descreve vantagens de custos de transação entre grandes e pequenos produtores, para demonstrar que os pequenos produtores possuem pelo menos três benefícios: (a) supervisão trabalhista não qualificada, (b) conhecimento local, (c) compra de alimentos e subsistência ao risco (WIGGINS, 2009, p. 4).

Assim, Wiggins (2009) conclui seu trabalho em termos de políticas públicas atendendo a três condições para desenvolver a pequena produção. Em primeiro lugar, criar um ambiente favorável para o investimento dos pequenos produtores em temas sensíveis como suprimentos, acesso ao crédito e importação de alimentos -efeito dumping. Em segundo lugar, investimento em bens públicos que deem suporte aos temas agrícolas como: educação, saúde, vias, irrigação, entre outras. Em terceiro lugar, desenvolvimento de instituições econômicas para destinar e proteger os direitos da propriedade, facilitar o comércio, reduzir o risco e permitirá ação coletiva (WIGGINS, 2009, p. 4).

Num trabalho posterior e coletivo Hazel et al. (2010) discutem o futuro dos pequenos produtores, e, baseados nestes achados, consideram necessário definir as prioridades de política pública. Para estes autores, desde 2005 emergem várias problemáticas, podendo, os pequenos produtores, gerar respostas adequadas, quando estes são estimulados positivamente pelas políticas. Algumas destas problemáticas podem ser: concentração de mercados, mudança climática, aumento de preços dos alimentos e dos suprimentos agrícolas, queda de preços de commodities, mudanças nas políticas ambientais, entre outras. As políticas, devem então intervir as temáticas de importância assim: (a) apoio direto aos produtores, para além dos subsídios; (b) políticas para ajustar as falhas de mercado (por exemplo, desequilíbrio nos preços); (c) desenvolver infraestrutura da pesquisa e extensão; (d) flexibilidade das instituições para se adaptarem às mudanças e inovar; dentre as mais importantes.

Até este ponto pode-se afirmar que, as discussões acima apresentadas descrevem os desafios que enfrentam os camponeses, agricultores familiares ou pequenos produtores, frente as transformações econômicas e políticas da internacionalização, com ênfase a partir dos anos 
2000. Recentemente, há uma renovação da agenda política internacional como consequência do alcance (ou não) dos Objetivos de Desenvolvimento do Milênio-ODM- ${ }^{8}$. Assim, declarase o ano 2014 como o Ano Internacional da Agricultura Familiar (AIAF), gerando com isto um lobby internacional para promover novas políticas de desenvolvimento rural articuladas com a SAN. Logo, diversos estudos e divulgações têm agido num intento de sintetizar os efeitos adversos das políticas e uma proposta para pôr camponeses\pequenos produtoreslagricultores familiares na sua dimensão e contribuição. Em virtude disso, se observa uma convergência entre as categorias agricultura familiar, desenvolvimento rural e segurança alimentar, debate que se sintetiza nas páginas seguintes.

Diante disso, o AIAF caracteriza-se pelo alto fluxo de produção acadêmica através do uso frequente da categoria agricultura familiar. Assim, é de interesse classificar as discussões segundo as linhas de debate propostas. Uma primeira linha de pensamento, enfatiza na definição da categoria agricultura familiar e suas convergências /divergências com os conceitos camponês e/ou pequeno produtor (FIDA; RIMISP, 2014; SALCEDO; OZ; GUZMÁN, 2014; SCHNEIDER; ESCHER, 2012). Para estes autores a categoria agricultura familiar denota uma construção social e política tecida historicamente. Suas raízes são evidenciadas no uso do termo "economia camponesa" de Chayanov e o termo "paysanne" na França do século XIX. Na América Latina o termo partiu do entendimento da Unidade Agrícola Familiar, entendida a partir da capacidade de um estabelecimento rural de atingir as necessidades de uma família. Por sua vez, o conceito camponês, fortemente atrelado à ideia de economia camponesa chayanoviana, teve sua máxima expressão nas discussões acadêmicas e políticas de 1970 e 1980, reconhecido como um setor social exposto à marginalidade e à pobreza (SALCEDO; OZ; GUZMÁN, 2014).

Parte da discussão emerge com a ideia de contribuir para a construção de uma tipificação ou categorização da agricultura familiar na América Latina e, portanto, na possibilidade de edificar referentes para as políticas públicas. Há, em consequência, uma diferenciação entre autores neste sentido. De um lado, Salcedo, Oz e Guzmán (2014), evidenciam três critérios convergentes na definição da agricultura familiar na região: a) na

\footnotetext{
${ }^{8}$ No ano 2000, constituídos por 8 objetivos, e agora relançados como ODS constituído por 16. Em geral e segundo o site da Agenda 2030, o objetivo principal destes era exercer uma pressão sob os governos do mundo para melhorar as condições de vida das pessoas, principalmente, o combate à fome e à pobreza (PNUD, 2015).
} 
lavoura prevalece o trabalho familiar; b) a gestão se encontra sob a chefia do lar; c) o tamanho da exploração é chave para sua categorização. No caso do Brasil e o Chile, além destes critérios, a renda deve ser do estabelecimento.

Por sua vez (FIDA; RIMISP, 2014; SCHNEIDER; ESCHER, 2012), reconhecem que uma categorização da agricultura familiar poderia ser realizada a partir de critérios acadêmicos, empírico/normativos ou políticos. Nos primeiros, prevalece uma motivação heurística, baseada em perspectivas epistemológicas e analíticas. Nos segundos, uma motivação pragmática, de padronização a partir de elementos como o acesso à terra, níveis de renda e grau de especialização. Nos terceiros, busca-se retomar uma categoria construída socialmente e com origem na organização política e na ação. Neste sentido, os autores expressam a percepção de que "[...] unidades no son necesariamente ni pobres, ni pequeñas, ni mucho menos desconectadas de los mercados, de las ciudades y de la dinámica social más general, lo que conlleva a generar conexiones con el estado nacional (a través de las políticas públicas) y, de manera más general, con la globalización socio-cultural" (FIDA; RIMISP, 2014, p. 8). Em consequência, a agricultura familiar é uma atividade econômica desenvolvida por um grupo social que gera produtos, bens e serviços e esse grupo é unido a través de laços de parentesco (SCHNEIDER; ESCHER, 2012).

Uma segunda linha é focada no estudo da diversidade da agricultura familiar (BELIERES et al., 2014; FIDA; RIMISP, 2014; VALLE, 2014). Assim Belieres et al. (2014), no texto intitulado Les agricultures familiales $d u$ monde, apresentam uma elaboração refinada em termos de agenda de políticas públicas. Neste documento os autores partem de uma diferenciação da agricultura familiar, tanto da agricultura patronal, quanto da agricultura empresarial, e das múltiplas definições da agricultura familiar nos contextos da América do Sul e América Central. Desta forma, concluem com uma definição baseada na multiplicidade da agricultura familiar a partir de vários parâmetros, entre os quais poderíamos destacar estes : o acesso aos recursos naturais, a capacidade de orçamento, o autoconsumo, a inserção nos mercados, o sistema de atividades e de produção, a mão de obra e o vínculo orgânico entre família e produção.

Para o caso das políticas de desenvolvimento rural Beliers et al. (2014), descrevem quatro políticas que têm em comum uma dimensão rural, permitindo assim refletir, sobre os desafios que se enfrentam. Segundo os autores existem, pelo menos quatro tipos de políticas: (1) setoriais de apoio à agricultura; (2) ambientais; (3) sociais; (4) territoriais de dotação de 
bens públicos. Os mesmos autores afirmam que nos países em desenvolvimento estas políticas estão focadas na luta contra a pobreza e contém instrumentos de política tais como: a desregulação nacional em favor da governabilidade dos atores internacionais, estruturas de supervisão de preços, a questão territorial, estratégias para se contrapor na afetação das políticas agrícolas nacionais pelo comércio internacional e, as bonificações sobre os juros, entre outros. Porém, para eles, dois aspectos merecem a atenção: o primeiro, positivo, ao conseguir um abandono da lógica setorial das políticas agrícolas. O segundo, negativo, ao considerar uma "empresarização" da agricultura familiar e, com este, seu desaparecimento (p. 136-151).

No caso do Equador, mesmo com a impossibilidade de uma definição única da agricultura familiar, há três critérios em comum entre os teóricos da categoria. Primeiro, a relação flexível entre trabalho familiar e a unidade de produção; segundo, os vínculos entre a unidade de produção e o mercado; terceiro, a participação das formas "híbridas" de produção (VALLE, 2014, p. 58). Devido ao viés que criam estes critérios, Valle (2014) optou pela utilização das variáveis: 1) mão de obra familiar e 2) atividade agropecuária para visibilizar a diversidade da agricultura familiar no país andino. $\mathrm{O}$ autor parte da clássica diferenciação entre agricultura de subsistência (também associada aos camponeses), de transição e consolidada, evidenciando uma forte presença na primeira (62\%), seguida da transição (37\%) que sumam 730 mil estabelecimentos agropecuários e em torno de 4.442 .875 hectares. A novidade deste autor está em evidenciar a importância dos ingressos não agropecuários na manutenção da família como: rendas empregatícias, atividades não agrícolas, subsídios, remessas e auxílios (VALLE, 2014). Em consequência, a diversidade responde tanto no âmbito territorial, populacional, da fonte de renda e das atividades desenvolvidas pelos agricultores familiares.

No caso do estudo de FIDA e RIMISP para América Latina, a diversidade, muito além da heterogeneidade dos sistemas agrários, está constituída pela mistura resultante dos tipos de agricultura familiar, assim, por exemplo, uma pessoa que é morador rural mais que sua atividade principal não é a agricultura, gera um tipo específico de agricultura familiar; ou uma pessoa que capta várias fontes de renda ao serem a agrícola uma delas (50\%) e morar na ruralidade. Além disso, a diversidade também está relacionada com a sua geolocalização ao gerar com isso tipos de performance econômico. 
Uma terceira linha, que especifica as diversidades regionais, nacionais e locais e, neste sentido, o papel das políticas de desenvolvimento territorial rural. Schejtman e Berdegué (2004), pioneiros no posicionamento do desenvolvimento territorial rural na América Latina, propunham este enfoque desde o processo de transformação produtiva e institucional de um espaço rural específico com o fim de reduzir a pobreza rural. Para esse fim, é pertinente desenhar políticas públicas focadas nas mudanças necessárias e, desta forma, rever a dimensão da transformação produtiva e do desenvolvimento institucional. Em relação a esta proposta, se bem ela não está desenhada especificamente para a agricultura familiar, tem no bojo o interesse em uma intervenção dos territórios, atendendo a sua diversidade em termos de atores, de sistemas de produção, de arquitetura institucional e o combate à pobreza.

Um estudo mais recente (SABORIN et al., 2014), demonstra a diversidade da agricultura familiar em função da heterogeneidade das políticas geradas na América Latina para esta categoria social e política. Estes autores abordam a diferenciação das políticas públicas a partir da identificação na disseminação de modelos de políticas e a susceptibilidade das agriculturas familiar às políticas agrícolas segundo o país. Para eles, a atividade agrícola é de importância para a região ao constituírem em torno do 75-90\% das unidades produtivas. Uma questão importante abordada pelos autores desta série é como o modelo brasileiro tornou-se suscetível de ser fixado em outros territórios pelo efeito de governos com ideias semelhantes, representadas no Mercosul ou pela circulação de ideias nos organismos multilaterais como FAO, BM, BID, FIDA e o IICA.

No que concerne às políticas de desenvolvimento territorial rural há inovações desde a gestão das políticas públicas, já que estas deveriam captar as especificidades dos ambientes e dos sistemas produtivos. Neste sentido, para a execução, são gerados instrumentos multi sectoriais de desenvolvimento rural e de planificação regional. Em geral, as políticas territoriais, notadamente, no Brasil, Chile, Costa Rica, México e Uruguai, priorizaram a agricultura familiar e visam reequilibrar os espaços mais marginalizados e com maiores índices de pobreza, porém, seu foco na agricultura gera um ênfase nas atividades agropecuárias em deterioro de outro tipo de atividades que poderiam ser desenvolvidas no âmbito rural (SABORIN et al., 2014).

Em suma, as discussões sobre a agricultura familiar têm iniciado sob a velha diferenciação entre camponeses e agricultores familiares, os primeiros concebidos como tradicionais e adversos à mudança, os segundos, modernos, e, portanto, público alvo de 
intervenções através das políticas públicas. Estas políticas têm se focado nos processos de modernização, aumento da produtividade e, em geral, dinâmicas de mercantilização. Paralelamente, a internacionalização, cada vez maior, das economias, gerou desajustes entre essas pequenas economias que apenas começam a ser corrigidas. Um passo nesta direção foi a comemoração do AIAF em 2014, promovendo uma agenda internacional que integra a produção sustentável, alimentação e combate à fome. Assim, para demonstrar algumas destas reconfigurações o exemplo da Colômbia pode ser ilustrador.

\section{AGRICULTURA FAMILIAR, DESENVOLVIMENTO RURAL E SEGURANÇA ALIMENTAR NA COLÔMBIA: DEBATES E POLÍTICAS PÚBLICAS}

Vários elementos do contexto colombiano e internacional têm contribuído para o debate e a mudança nas políticas de SAN, para propor a agricultura familiar como elemento que articula segurança alimentar e desenvolvimento rural no país. No contexto nacional, o início dos diálogos de paz ocorrem em 2012, a paralisação agrária e a criação da Missão para a Transformação do Campo, em 2013. Neste contexto é de interesse salientar que se observa uma reconfiguração das políticas para a ruralidade que visam diminuir a brecha campo-cidade e melhorar as condições dos territórios declarados de pós-conflito. No contexto internacional, pode-se destacar a comemoração do Ano Internacional da Agricultura Familiar -AIAF- em 2014.

\section{O antecedente: a Política Nacional de Segurança Alimentar e Nutricional}

No ano de 2007 foi criada a política nacional de segurança alimentar mediante o documento Conpes social $113^{9}$. Neste texto são contempladas as diretrizes em matéria de segurança alimentar e nutricional, se definem estratégias e metas a serem executadas pelos departamentos e municípios, e, determinam-se os itens de orçamento e as fontes para financiar a política. No seu momento, a política definiu a SAN a partir de quatro dimensões: (1) disponibilidade; (2) acesso; (3) qualidade e inocuidade; (4) adequada utilização biológica.

\footnotetext{
${ }^{9}$ Existe no país uma diferenciação de documentos Conpes social e Conpes econômico, este último de maior importância que o primeiro.
} 
Isto implicaria que as pessoas tivessem segurança alimentar quando elas conseguissem ter uma alimentação suficiente, adequada e oportuna (COLOMBIA. DNP, 2007).

Especificamente, no componente de disponibilidade e de importância para o desenvolvimento rural, a política diagnosticou fraquezas com relação à oferta suficiente e estável de alimentos da seguinte forma: (1) intensa importação de alimentos da cesta básica; (2) problemas na distribuição interna dos alimentos; (3) deficiências no uso dos fatores produtivos; (4) acesso às sementes certificadas; (5) falta de acesso ao crédito; (6) baixo rendimento dos cultivos; (7) alto custo do transporte e atravessadores que incrementam os preços; (8)e em relação à qualidade e inocuidade: má qualidade das matérias primas, contaminação biológica, e cumprimento parcial das Boas Práticas Agrícolas e as Boas Práticas de Fabricação (COLOMBIA. DNP, 2007, p. 20-21).

Além disso, definiu-se como critério de focalização os grupos de população "mais vulneráveis" tais como: deslocados pela violência, atingidos pelos desastres naturais, grupos étnicos, crianças, mulheres gestantes e lactantes e camponeses de baixa renda. Da mesma forma, o documento define uma série de responsabilidades ${ }^{10}$ e ações nos distintos níveis de governo: (a) o DNP e o MADR, deve criar critérios de escolha entre os principais produtos alimentares a serem promovidos para a produção e regulado o preço por serem da cesta básica; (b) a Superintendência de Industria e Comercio, deve realizar pesquisas e atue nos casos que existem falhas no mercado agroalimentar; (c) o MADR deve contribuir na vigilância de preços dos insumos agropecuários; (d) as entidades territoriais devem contribuir na melhoria dos sistemas de comercialização dos pequenos e médios produtores, o governo nacional, por sua vez, deve desenhar os instrumentos de política tributários na integração das cadeias produtivas e a redução dos níveis de intermediação (COLOMBIA. DNP, 2007, p. 33-34).

De acordo com as dezesseis metas estabelecidas, a política esteve orientada prioritariamente em ações para combater a desnutrição crônica ou aguda, tanto em crianças, quanto em gestantes, questão que pode ser comprovada nos seguintes indicadores: a) aumentar cobertura desayunos infantiles, b) aumentar cobertura universal alimentación escolar, c) reducir desnutrición global, e) reducir desnutrición crónica, f) reducir prevalência desnutrición aguda, g) reducir muertes por desnutrición, h) reducir prevalencia

\footnotetext{
${ }^{10}$ Segundo o documento Conpes a política deverá ser coordenada pelo Ministério de Saúde e pelo Ministério de Agricultura e Desenvolvimento Rural.
} 
anemia, i) aumentar meses de lactancia. Na prática, este viés se concretizou em três linhas de ação. A primeira, a construção de Centros de Recuperação Nutricional em várias regiões e departamentos. A segunda, em forma de subsídios, seja através da cesta de básica (bolsa de família), ou no fornecimento de alimentos nas escolas (merenda escolar). A terceira, com a criação de hortas (huertas) do lar ou escolares para garantir o autoconsumo (COLOMBIA. DNP, 2007, p. 41-42).

Por exemplo, numa avaliação da execução da política no departamento de Antioquia foi demonstrado que o plano departamental de segurança alimentar MANÁ se configurou a partir de uma visão excludente do acesso à alimentação, e que desconheceu a multidimensionalidade do tema alimentar (CALDERÓN; HERRERA, 2012). Assim, e segundo o plano nacional de segurança alimentar e nutricional -PNSAN 2012-2019-, a política foi um exemplo de assistencialismo, ações desagregadas e setoriais que não levaram em conta os linhamentos do documento Conpes 113 (COLOMBIA; CISAN, 2013, p. 13)

Além disso e segundo os entrevistados por Calderón e Herrera (2012), questionaram que a política se concentrou nos critérios de eficiência e baixo custo dos alimentos fornecidos, por exemplo, nas cantinas escolares e isso gerou dinâmicas como transportar alimentos, às vezes estragados, até as zonas rurais onde facilmente estes poderiam ser plantados. Recentemente, tem se demonstrado que não só os alimentos in natura eram transportados de um território para outro, também, que os produtos fornecidos na alimentação escolar vinham de outros países, como o feijão da China $^{11}$, produto que, por demais, existe em grande produção e de alta qualidade no departamento e várias regiões do país.

Depois, uma avaliação institucional da política de SAN, concluiu que os avanços em segurança alimentar foram poucos, mas, especificamente a questão da produção de alimentos consolidou-se como aquela de maior fragilidade em termos de ações governamentais. Além de que a meta não foi atingida, pois o número de hectares cultivadas em alimentos em vez de aumentar, diminuiu, passando de 3.878.884 ha em 2006 até 3.842 .176 ha em 2010 (COLOMBIA. DNP, 2015, p. 169). O país consolidou-se como um importador líquido de alimentos e, isto é, daqueles que fazem parte do grupo de alimentos prioritários.

Além dos aspectos já apontados pela avaliação, o MADR demorou mais de cinco anos em formular o plano nacional de SAN, plano que tinha por objetivo desenhar os programas e

\footnotetext{
${ }^{11}$ Vários entrevistados têm comentado que esse feijão poderia ser inclusive do Brasil.
} 
projetos para executar a política nos territórios, e, portanto, contribuiu a um maior atraso deste processo político. Até então, o conceito camponês era substituído pelo pequeno produtor, e as políticas orientadas para esta população estavam em desuso por esse momento.

\section{A entrada em cena da Agricultura familiar: debates políticos, técnicos e institucionais}

A categoria agricultura familiar constitui uma importação conceitual proveniente da confluência de vários discursos ${ }^{12}$ na Colômbia. Historicamente o debate tem sido construído em relação ao camponês como categoria social e política, e o pequeno produtor como suscetível de apoio do Estado através de políticas, em particular, de crédito e acesso à terra (COMITÉ DE INTEGRACIÓN SALSA BOGOTÁ-CUNDINAMARCA, 2015; MACHADO; BOTELLO, 2013; COLOMBIA. MISIÓN PARA LA TRANSFORMACIÓN DEL CAMPO, 2015) ${ }^{13}$. É comum, também, tratar o conceito economia camponesa para fazer referência a uma economia de subsistência e, de forma recente, por conta dos diálogos de paz entre o governo e as FARC, se alude à economia camponesa, familiar e comunitária como um todo (MACHADO; BOTELLO, 2013).

\footnotetext{
...en este momento hemos tenido inconvenientes de carácter técnico y político en la medida en que hay varias definiciones que parecen referirse a la misma población, pero no está tan claro cuáles son las diferencias, particularmente frente a agricultura familiar, economía propia y economía campesina. Entonces, el despacho del Viceministro Días Granados de Desarrollo Rural, en el marco de un acuerdo que tiene el Ministerio con FAO, estableció unas mesas de trabajo de entidades del sector público, sociedad civil, congreso, universidades y organismos de cooperación que buscaran hacer unas recomendaciones de política sobre agricultura familiar (ENTREVISTA 20C, 2017).
}

A partir de 2014, observa-se uma convergência no uso do termo agricultura familiar entre os discursos social, acadêmico e institucional, porém, com algumas nuances. Da perspectiva social, predomina a defesa pelo conceito camponês em contraposição à agricultura familiar e soberania alimentar, em contraste com a segurança alimentar (COMITÉ

12 Da FAO com ocasião do Ano Internacional da Agricultura Familiar, dos diálogos FIDAMERCOSUL, das organizações sociais, especificamente as brasileiras, entre outros.

${ }^{13} \mathrm{Um}$ antecedente interessante é a afirmação de Eric Saborin propondo que na Colômbia não existe o conceito agricultura familiar, mas, que desde o ano 1989 vem se falando de Unidad Agrícola Familiar UAF- no país, que constitui o tamanho de uma propriedade que permite a subsistência da família (GRISA; SABORIN, 2019). 
DE INTEGRACIÓN SALSA BOGOTÁ-CUNDINAMARCA, 2015), de um lado; e, de outro, no reconhecimento da diversidade populacional e territorial da agricultura familiar (COMITÉ NACIONAL DE IMPULSO -COLOMBIA-, 2014).

$\mathrm{Na}$ perspectiva acadêmica, a discussão situa-se em duas dimensões: a primeira produtiva-política, de multifuncionalidade da agricultura familiar (ACEVEDO OSORIO; COLLAZOS, 2016; CAÑAS-GIRALDO; BEDOYA-PATIÑO; CÁRDENAS-GRAJALES, 2015; COLLAZOS, 2016), a reconfiguração das políticas públicas para o setor rural (NIÑO MARTÍNEZ, 2015; RAMOS, 2016), e do nível de especialização da agricultura familiar (MACHADO; BOTELLO, 2013); a segunda de uma crítica tanto aos discursos de desenvolvimento territorial e produtivista, em contraste com o resgate das categorias: camponês, soberania alimentar e bem viver (buen vivir) (HERRERA-JARAMILLO et al., 2015).

Na perspectiva institucional, os estudos e discursos têm se encaminhado em várias vias. Uma primeira, de reconhecimento da multidimensionalidade do camponês em relação às questões ambientais, econômicas, sociais e culturais (COLOMBIA. SUBGERENCIA DE TIERRAS. INCODER, 2013). Uma segunda, da importância das contribuições na produção de alimentos, a segurança alimentar e o cuidado do meio ambiente (IICA, 2015; COLOMBIA. MISIÓN PARA LA TRANSFORMACIÓN DEL CAMPO, 2015). Uma terceira, no resgate das contribuições das mulheres nas dinâmicas agrícolas e rurais (COLOMBIA. MINSALUD; FAO, 2015). Uma quarta, em relação a agricultura familiar agroecológica campesina (COLOMBIA. UPRA, 2015). E, por fim, da eficiência dos processos produtivos e de trocas comerciais que demonstraram maiores níveis de produtividade em relação aos grandes produtores do país (PERFETTI et al., 2013).

Hoje o discurso social, académico e institucional estão agrupados na Mesa Técnica para Agricultura Familiar ${ }^{14}$, espaço criado em 2014 e reativado em 2017, liderado pela dupla FAO-UPRA, que iniciou a partir da definição de um consenso entre economia própria, economia camponesa e agricultura familiar. Por fim, o discurso da agricultura familiar chegou

\footnotetext{
${ }^{14}$ Em entrevista, o Ministério de Agricultura expõe que o processo de construção da política pública para agricultura familiar através da Mesa Técnica para a Agricultura Familiar tem iniciado para discutir e definir entre organizações campesinas, academia, FAO e institucionalidade, um consenso em relação ao conceito a considerar na política pública. Três posições foram identificadas nesse momento: de um lado, a institucional, que segue as diretrizes da FAO e os debates internacionais com o conceito agricultura familiar; da ANUC, que propõe o conceito economia própria; da academia e um setor majoritário da sociedade civil que inclina-se por economia campesina.
} 
atrelado a duas perguntas, a primeira, como alimentar mais de seis milhões de pessoas no mundo? E, a segunda, como fazer isso de forma sustentável? Estas perguntas foram a base internacional da mudança na política SAN que visou articular a superação da pobreza e o desenvolvimento rural.

[...]hay una preocupación digamos general de diseño de política en donde ya se ha identificado el tema de comercialización y compras públicas, en especial, en lo que corresponde a agricultura familiar que hace parte, precisamente, de una discusión mucho más amplia que tiene que ver con el tema de desarrollo rural y agricultura familiar, que está sucediendo en este momento en torno al trabajo del cual recibimos acompañamiento de $\mathrm{FAO}$; y en términos prácticos, hay unos acercamientos con todos estos sectores que mencioné tratando de explorar las posibilidades que permitan digamos generar en el nivel nacional una política de compras públicas que ojalá no solo beneficie a las organizaciones de los gremios, sino también a la de agricultura familiar, vinculándolo con otras políticas estatales: superación de la pobreza, política social, y en este momento dentro de esas posibilidades ciertamente de vínculo, por lo menos hasta ahora yo lo único que he descubierto es a través del mecanismo de compras públicas, digamos, es el mecanismo de compras públicas el que podría ser llamado potencialmente a ser el instrumento que vincule esos dos ámbitos de trabajo. (ENTREVISTA 20C, 2017)

\section{A mudança das policy: da SAN ao desenvolvimento rural para Agricultura Familiar}

As políticas rurais na Colômbia estão mudando. Grande parte dessas transformações acontecem nas políticas sociais, ao mesmo tempo em que o país tenta recuperar a institucionalidade rural que foi extinta com maior força nos anos 2000. Para demonstrar essa renovação, esta seção foi construída a partir de três documentos principais e atuais que definem as diretrizes de desenvolvimento rural para os seguintes anos, listados a seguir: a) Plano Nacional de Segurança Alimentar PNSAN 2012-2019; b) Diretrizes para a Agricultura Familiar UPRA; c) Acordo final de Paz. Para tanto, o texto está construído em termos de mudança institucional, sublinhando aquelas ideias, do giro nas políticas públicas de SAN.

O PNSAN 2012-2019, foi o primeiro documento governamental com uma visão intersetorial da SAN. Este instrumento teve por objetivo geral: "Contribuir al mejoramiento de la situación alimentaria y nutricional de toda la población colombiana, en especial, de la más pobre y vulnerable” (COLOMBIA. CISAN, 2013). E entre outros objetivos específicos, ter uma oferta suficiente, acesso aos alimentos definidos como prioritários e atingir a meta de que a população colombiana consuma uma alimentação completa, equilibrada, suficiente e adequada (COLOMBIA. CISAN, 2013). 
A diferença das ações para combater a desnutrição crônica ou aguda, tanto em crianças, quanto em gestantes, como visou o Conpes 113, o plano concentrou-se em orientar suas estratégias para aumentar a produção de alimentos prioritários ${ }^{15}$. Para este fim, desenharam-se 5 estratégias para desenvolver a institucionalidade na SAN, criar planos territoriais, alianças produtivas e fortalecer a participação social, entre outras. Especificamente, das 34 metas estabelecidas nos eixos de disponibilidade, acesso, consumo, aproveitamento biológico e inocuidade, 26,5\% correspondem a temas agropecuários propriamente ditos no componente de disponibilidade (COLOMBIA. CISAN, 2013; COLOMBIA. DNP, 2007). Os resultados desta ação podem ser evidenciados no Gráfico 1 que apresenta o aumento da área plantada que, como comentado em páginas anteriores, diminuiu drasticamente entre os anos 2007 e 2012.

15 O grupo de alimentos prioritários é constituído por cereais, grãos, legumes e frutas, tubérculos, açúcares, cacau e laticínios. 
Gráfico 1. Produção nacional em hectares plantados 2014-2016

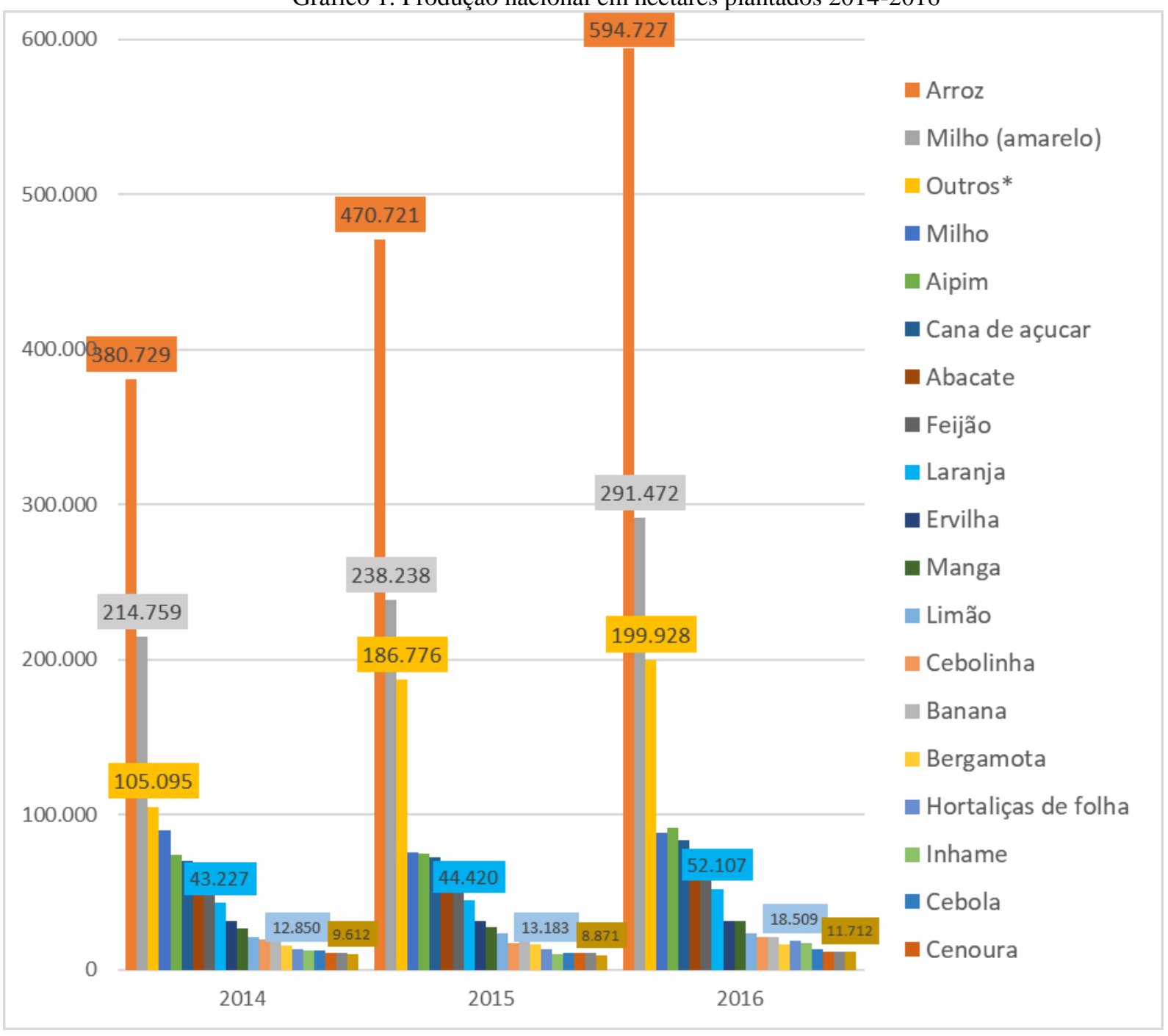

Fonte: Elaboração a partir de (COLOMBIA. MINAGRICULTURA, 2017)

Estes indicadores constituíram o mecanismo para mensurar o avanço em produção alimentar, entre os quais foram definidos os seguintes: a) área plantada em Grupo de Alimentos Prioritarios (ha); b) área coletada Grupo de Alimentos Prioritarios (ha); c) produção Grupo de Alimentos Prioritarios (t); d) rendimento Grupo de Alimentos Prioritarios (t/ha); e) produção pecuária (t) (COLOMBIA. CISAN, 2013). Além disso, e, como parte da estratégia de desenvolver institucionalidade, o MADR criou uma diretoria de capacidades produtivas e geração de renda, órgão que é responsável pela assistência técnica da produção de alimentos da agricultura familiar (COLOMBIA. UPRA, 2015). O Plano, portanto, constituiu uma ferramenta de articulação dos diferentes setores e programas em 
SAN ao interior do governo, ao mesmo tempo em que priorizou o apoio aos pequenos produtores como garantes da produção de alimentos no país.

Anos mais tarde, em 2015, foram elaboradas as diretrizes para a agricultura familiar pela UPRA. Salienta-se nas primeiras páginas deste texto o conceito Agricultura Familiar de Base Agroecológica (AFBA) e considera-se uma boa opção para promover a segurança alimentar, contribuir ao uso eficiente do solo, conservar a biodiversidade e fornecer serviços ecossistêmicos. Como elemento central do documento, foi desenhado um plano de execução que teve por objetivo "[...] contribuir al mejoramiento de las condiciones de vida de los agricultores familiares colombianos" (UPRA, 2015, p. 80).

Especificamente, entre os indicadores de efetividade definidos pela entidade se contemplam: 1) número de famílias em transição agroecológica; 2) grau de segurança alimentar na zona de execução da política; 3) índices de agrobiodiversidade e diversidade; 4) número de mulheres e jovens envolvidos nas ações; 5) número de políticas desenhadas e aprovadas que potencializam a AFBA. Vale a pena salientar que no país não há referências antigas em políticas que favoreçam a agroecologia, a principal referência em políticas para campesinos e/ou pequenos produtores estava constituída pela lei 160 de 1994, que focou-se em criar os mecanismos para o acesso à terras e crédito por parte dos campesinos pobres. Até então, esta política não considerava uma articulação entre camponeses e SAN.

Ainda, o momento chave dessa articulação da SAN, desenvolvimento rural e agricultura familiar, consolidou-se com a assinatura dos acordos de paz em novembro de 2016. O Acordo definiu como um dos pontos de discussão uma Reforma Rural Integral -RRI (Ver Ilustração 1), sendo levado em consideração, temas de interesse histórico, como por exemplo: o acesso à terra, programas de desenvolvimento rural com enfoque territorial e, em geral, a execução de planos nacionais para garantir o acesso integral a todos os direitos como saúde, educação, vias, água, dentre outros. 


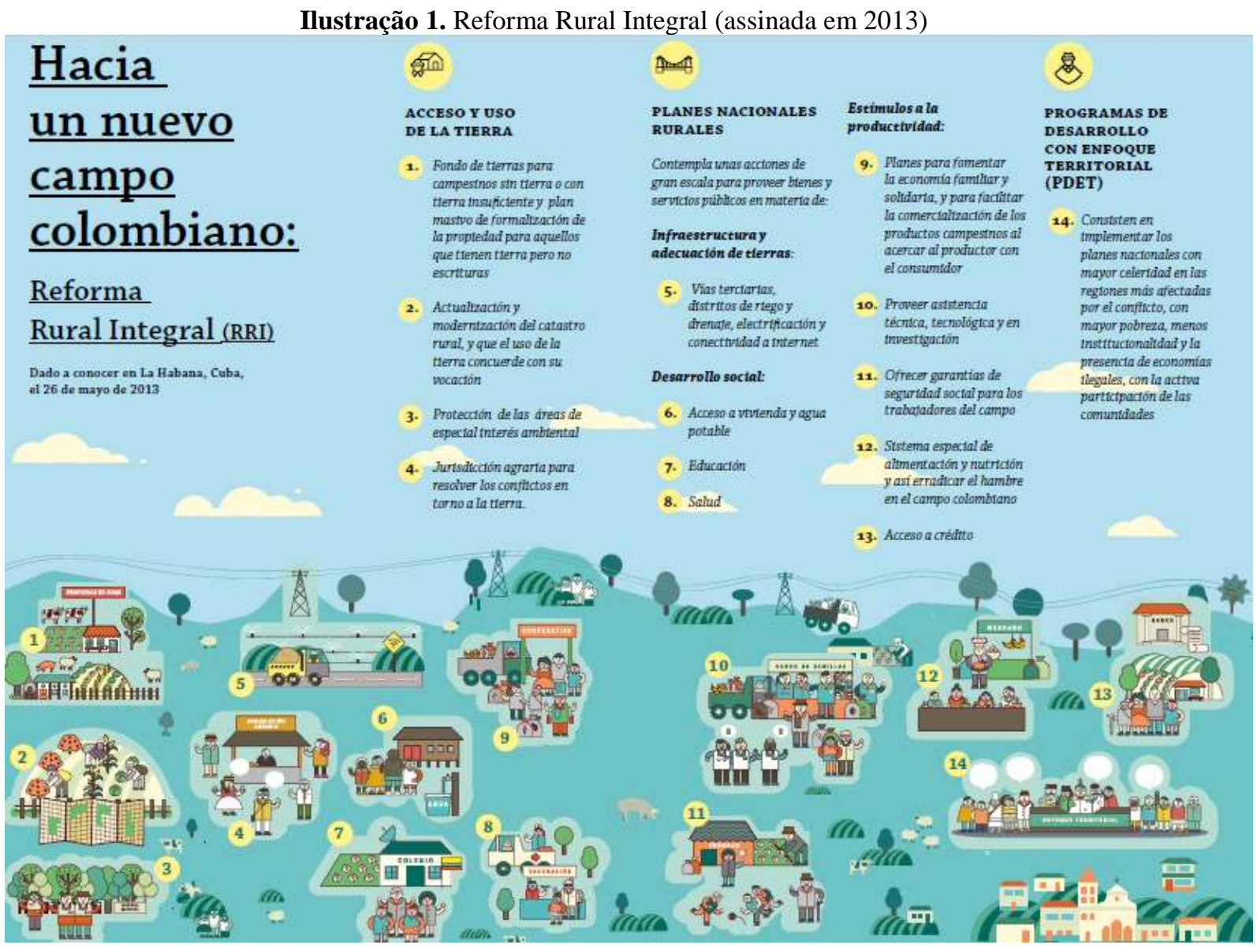

Fonte: (COLOMBIA. OFICINA DEL ALTO COMISIONADO PARA LA PAZ, 2016, p. 4-5)

Da mesma forma, desenhou-se um sistema para atingir de forma gradativa o direito à alimentação. Como ponto de partida deste sistema, foi identificada a importância de uma política alimentar e nutricional diferenciada para as áreas rurais que entrelaçam o aumento gradativo da produção de alimentos, geração de renda e melhoria das condições de vida. Estes devem ser executados mediante planos "estaduais" e locais de alimentação que teriam a participação da sociedade, dos governos locais e o governo nacional; a criação do Conselho Nacional de Alimentação e Nutrição, com ampla participação das comunidades, cujas funções serão: propor as diretrizes de política alimentar, coordenar os planos por departamento e realizar seguimento e avaliação dos avanços das metas (SANTOS; JIMÉNEZ, 2016).

Além das questões mais operativas, esta política alimentar deverá considerar aspectos como: a) desenvolver programas para combater a fome e a desnutrição; b) executar apoios para fortalecer e afiançar a produção e o mercado interno; c) promover mercados locais e regionais; d) campanhas publicitárias para promover a produção e o consumo de alimentos 
saudáveis; e) desenhar incentivos à produção e comercialização, que incluam, subsídios nos casos de afetação pela internacionalização da economia (SANTOS; JIMÉNEZ, 2016).

Alguns dos resultados, são apresentados na Tabela 1. Mesmo que ainda tímidos e numa fase de definição e desenho de instrumentos para executar as ações, observa-se uma forte participação da linha de comercialização, salientando que são explicitados mecanismos focados na participação da ACFC.

Tabela 1. Resultados da Reforma Rural Integral -RRI- 2018

\begin{tabular}{|c|c|c|c|}
\hline Linhas & Ações & Orçamento & População beneficiária \\
\hline Crédito & $\begin{array}{l}\text { Linha especial de } \\
\text { Crédito } \\
\text { Créditos flexíveis }\end{array}$ & N/D & $\begin{array}{l}\text { Pequenos, médios } \mathrm{e} \\
\text { grandes produtores, jovens, } \\
\text { mulheres, vítimas do } \\
\text { conflito } \\
\text { quilombolas }\end{array}$ \\
\hline Seguros de colheita & $\begin{array}{c}\text { Seguro } \\
\text { subsidiado da } \\
\text { colheita da ACFC }\end{array}$ & 12 mil USD & $\begin{array}{l}\text { Áreas produtoras } \\
\text { de milho branco crioulo e } \\
\text { banana da terra }\end{array}$ \\
\hline $\begin{array}{l}\text { Moradia } \\
\text { rural }\end{array}$ & $\begin{array}{c}\text { Moradia } \\
\text { nova e melhorias em } \\
\text { outras }\end{array}$ & $\begin{array}{l}8.184 \\
\text { subsídios }\end{array}$ & \\
\hline $\begin{array}{l}\text { Acesso à } \\
\text { terra }\end{array}$ & $\begin{array}{l}\text { Formular lei } \\
\text { para estimular outros } \\
\text { mecanismos de } \\
\text { acesso à terra }\end{array}$ & N/A & N/A \\
\hline $\begin{array}{l}\text { Conflitos } \\
\text { de terras (uso x } \\
\text { vocação) }\end{array}$ & $\begin{array}{l}\text { Desenho de } \\
\text { instrumentos de } \\
\text { regulamentação do } \\
\text { uso e gestão da terra. } \\
\text { Demarcação da } \\
\text { fronteira } \\
\text { agropecuária }\end{array}$ & N/D & $\begin{array}{l}\text { Moradores de } \\
\text { áreas estabelecidas e } \\
\text { demarcadas }\end{array}$ \\
\hline $\begin{array}{l}\text { Comerciali } \\
\text { zação }\end{array}$ & $\begin{array}{l}\text { 1. Desenho } \\
\text { Estratégia Nacional } \\
\text { de Comercialização } \\
\text { (Agência de }\end{array}$ & N/A & N/A \\
\hline
\end{tabular}




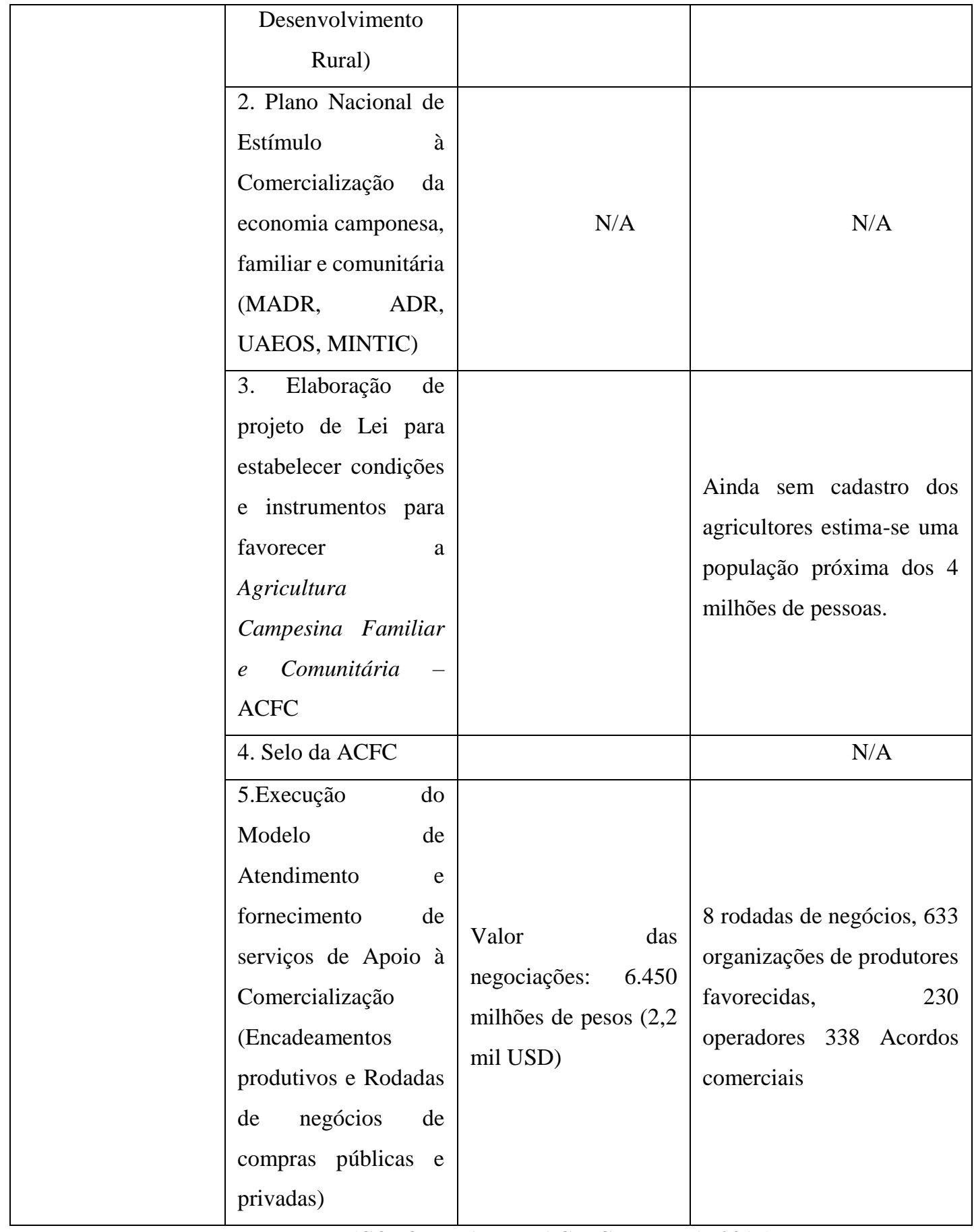

Fonte: (COLOMBIA. MINAGRICULTURA, 2019).

Em conclusão, a grande mudança que aconteceu no país na temática alimentar faz parte de um processo para articular as ações sobre segurança alimentar e nutricional com as intervenções em desenvolvimento rural. Em particular, reconhecendo o papel dos camponeses e agricultores familiares como atores principais na produção e fornecimento de alimentos. Para tanto, foram desenhados três instrumentos da política que definem as diretrizes em SAN 
para os seguintes anos, estes são: o PNSAN 2012-2019, as diretrizes em Agricultura Familiar da UPRA e os planos departamentais e locais de SAN, considerados no Acordo Final de Paz.

Neste sentido, a mudança das policy materializa-se numa transformação na concepção simples e unidimensional da questão alimentar como um problema de assistência social, isto é, levar alimentos para as pessoas famintas, para converter-se numa concepção ampla, multidimensional que enxerga a alimentação como uma temática de soberania nacional, garantindo a produção nacional de alimentos; de saúde, melhorando as condições de vida e diminuindo as doenças da população em geral; de educação, formando pessoas mais conscientes daquilo que consomem; e de desenvolvimento rural, melhorando as condições de vida dos produtores de alimentos.

\section{CONSIDERAÇÕES FINAIS}

Como foi demonstrado neste artigo, as políticas de segurança alimentar e nutricional tiveram uma transformação no seu objetivo, uma vez que passaram a priorizar a temática da disponibilidade de alimentos como questão chave para atingir uma alimentação adequada. Neste sentido, os camponeses tomaram importância como principais produtores de alimentos, ao mesmo tempo em que melhoraram suas condições de vida. A agricultura familiar, portanto, entra em cena como conceito fundamental para caracterizar, classificar e nomear o público alvo das políticas públicas, com ocasião da comemoração do AIAF. Como foi evidenciado, há uma multiplicação de estudos e pesquisas no ano 2014, que inclui diversas publicações para a América Latina.

Como comentado, o conceito de agricultura familiar tornou-se complexo no contexto colombiano e latino-americano, no entanto, no caso colombiano o Acordo de paz criou-se uma complexidade dupla, no reconhecimento de uma agricultura familiar, camponesa e comunitária. Esta complexidade também passou pela mudança nas políticas de desenvolvimento rural, ao considerar a segurança alimentar como um sistema, ou seja, um problema que precisa de um conjunto de políticas e programas territoriais que deem conta dessa complexidade. Desta forma, se compreende que a SAN só pode ser atingida quando sejam construídos os incentivos adequados para que os camponeses/agricultores familiares produzam alimentos. 
Não obstante, um dos grandes desafios que enfrenta a economia camponesa e/ou familiar e as políticas voltadas para esta população, são as fortes oposições dos setores políticos mais tradicionais, que avaliam toda política de desenvolvimento rural para pequenos produtores, como o Estado fazendo a revolução. Isto acontece com maior força quando o acesso à terra se torna epicentro de qualquer discussão rural.

Em contraste, e de forma alternativa, observa-se um tecido social mais forte entre os camponeses da Colômbia e o movimento social agrário da América Latina, especificamente, setores indígenas, quilombola e ambientalistas. Estas conexões ajudam exercendo uma pressão internacional sobre os legisladores e criando laços de conhecimento entre os diferentes grupos sociais.

\section{REFERÊNCIAS}

ACEVEDO OSORIO, A.; COLLAZOS, J. La Agricultura Familiar en Colombia. Estudios de caso desde la Multifuncionalidad y su aporte a la Paz. [s.l: s.n.].

ACEVEDO-OSORIO, Á.; SUÁREZ, J. P. C.; WAEGNER, J. K. Ideas para la transición hacia la sostenibilidad del sistema agroalimentario: agricultura familiar, agroecología y nichos sociotécnicos. In: La agroecología. Experiencias comunitarias para la Agricultura Familiar en Colombia. Bogotá: Corporación Universitaria de Minuto de Dios-Uniminuto; Editorial Universidad del Rosario, 2019. p. 13-34.

AECID; PROYECTO FOOD FACILITY HONDURAS. Seguridad alimentaria y nutricional. Conceptos básicos, 2011.

BELIERES, J.-F. et al. Les agricultures familiales du monde. Définitions, contributions et politiques publiques. Coquelicot: CIRAD, 2014.

CALDERÓN, P. E. G.; HERRERA, P. Debilidades y fortalezas de la política de seguridad alimentaria en Antioquia. In: 2012, Quito. Anais.. In: VI CONGRESO LATINOAMERICANO DE CIENCIA POLÍTICA. Quito: ALACIP, 2012.

CAÑAS-GIRALDO, W. A.; BEDOYA-PATIÑO, C. G.; CÁRDENAS-GRAJALES, G. I. Contribuciones de la agricultura familiar en Colombia desde el enfoque de la multifuncionalidad MFA: estudio de caso en la Asociación de moreros de Santa Rosa de Cabal MUSA, departamento de Risaralda (WP). Bogotá: Universidad Cooperativa de Colombia, 2015. Disponível em:

<http://revistas.ucc.edu.co/index.php/dotr/article/view/1085>. Acesso em: 12 dez. 2019.

CENTRO NACIONAL DE MEMORIA HISTÓRICA. Granada: Memorias de guerra, resistencia y reconstrucción. Bogotá: Centro Nacional de Memoria Histórica; Colciencias; Corporación Región, 2016. 
CHIRIBOGA, M. Desafíos de la pequeña agricultura familiar frente a la globalización: Boletín de intercambio. México D.F.: Centro Latinoamericano de Desarrollo RuralRIMISP, 2002.

COLLAZOS, J. M. Hacia nuevas políticas públicas para el fomento y protección de la agricultura familiar y la construcción de la paz en Colombia. In: OSORIO, Á. A. (Ed.). La agricultura familiar en Colombia. Estudios de caso desde la multifuncionalidad y su aporte a la paz. Bogotá: Universidad Cooperativa de Colombia; Corporación Universitaria Minuto de Dios: Agrosolidaria, 2016. p. 213-227.

COLOMBIA. CISAN. Plan Nacional de Seguridad Alimentaria y Nutricional (PNSAN) 2012-2019, 2013.

COLOMBIA. DNP. Documento Conpes 113. Política nacional de seguridad alimentaria y nutricional (PNSAN), 2007.

COLOMBIA. DNP. Evaluación institucional y de resultados de la política nacional de seguridad alimentaria y nutricional -PSAN -que permita identificar la capacidad institucional de las entidades a cargo de su formulación e implementación, a nivel nacional y territorial, e identificar el cumplimiento de los objetivos y el avance de las metas, de acuerdo a lo establecido en el Documento Conpes 113 de 2008-DNP 509 de 2014, DNP, 2015 .

COLOMBIA. MINSALUD; FAO. La mujer rural y la agricultura familiar en Colombia, 2015.

COLOMBIA. SUBGERENCIA DE TIERRAS. INCODER. Análisis de diferentes concepciones teóricas del campesino y sus formas de organización: Documento estratégico. Bogotá: Minagricultura;Incoder;Corporación Latinoamericana Misión Rural, 2013.

COLOMBIA. UPRA. Lineamientos para el Ordenamiento Productivo de la Agricultura Familiar con Base Agroecológica AFBA, 2015.

COMITÉ DE INTEGRACIÓN SALSA BOGOTÁ-CUNDINAMARCA. Manual de soberanía, autonomía y seguridad alimentaria para el Buen Vivir, 2015.

COMITÉ NACIONAL DE IMPULSO -COLOMBIA-. Definición de la agricultura familiar para Colombia, 2014. Disponível em:

<http://www.ruralfinanceandinvestment.org/sites/default/files/Agricultura\%20Familiar\%20 para\%20Colombia.pdf>. Acesso em: 5 nov. 2019.

ENTREVISTA 20C. Entrevista semiestructurada actor institucional. [s.1: s.n.]

ESCOBAR, Á. M. B. Recomendaciones y líneas de acción para la política pública de desarrollo rural en Colombia: Papers. Bogotá: Konrad Adenauer Stiftung, 2012. 
FIDA; RIMISP. La agricultura familiar en América Latina. Un nuevo análisis comparativo. Roma: FIDA; RIMISP, 2014.

G

RISA, C.; SABORIN, E. Agricultura familiar: de los conceptos a las políticas en América Latina y el Caribe: Alimentación, agricultura y desarrollo rural 2030/en América Latina y el Caribe. Santiago de Chile: Organización de las Naciones Unidas para la Agricultura y la Alimentación (FAO), 2019.

HAZEL, P. et al. The Future of Small Farms: Trajectories and Policy Priorities. World Development, [s. 1.], v. 38, n. 10, p. 1349-1361, 2010.

HERRERA-JARAMILLO, M. et al. Ni pequeño productor, ni agricultor familiar, soy campesino, 2015. Disponível em:

$<$ https://www.javerianacali.edu.co/sites/ujc/files/node/field-

documents/field_document_file/nipequenoproductor_4.pdf>. Acesso em: 12 dez. 2016.

IICA. Proponiendo nueva política pública para la agricultura familiar en Colombia., 2015.

Disponível em:

<http://www.iica.int/es/prensa/noticias/proponiendonuevapol\%C3\%ADticap\%C3\%BAblica paralaagriculturafamiliarencolombia>. Acesso em: 15 dez. 2016.

PARAGUAY. INSTITUTO NACIONAL DE DESARROLLO RURAL Y DE LA TIERRA. Desarrollo urbano y rural. Paraguay.

LONG, N.; LONG, A. Battlefields of Knowledge: The interlocking of the theory and practice in social research and development. Abingdon: Routledge, 1992.

MACHADO, A.; BOTELLO, S. La Agricultura Familiar en Colombia Informe del Proyecto Análisis de la Pobreza y de la Desigualdad en América Latina Rural: Documentos de trabajo. Santiago de Chile: Rimisp, 2013.

COLOMBIA. MINAGRICULTURA. Colombia Siembra superó su meta y alcanzó más de un millón de hectáreas nuevas. 2017. Disponível em:

$<$ https://www.minagricultura.gov.co/noticias/Paginas/Colombia-Siembra-super\%C3\%B3su-meta-.aspx>. Acesso em: 21 dez. 2019.

COLOMBIA. MINAGRICULTURA. Informe de rendición de cuentas de la construcción de paz. Enero 2018-Diciembre 2018. Bogotá: MADR, 2019.

COLOMBIA. MISIÓN PARA LA TRANSFORMACIÓN DEL CAMPO. El campo colombiano: Un camino hacia el bienestar y la paz, Departamento Nacional de Planeación, 2015.

NIÑO MARTÍNEZ, C. Contribución al debate conceptual y metodológico de la agricultura familiar campesina y el desarrollo rural en la política agraria colombiana. 2015. Trabajo de Grado (Facultad de Ciencias Agrarias) - Universidad Nacional de Colombia, Bogotá, 2015. 
COLOMBIA. OFICINA DEL ALTO COMISIONADO PARA LA PAZ. Lo que hemos acordado, 2016. Disponível em: <http://www.altocomisionadoparalapaz.gov.co>. Acesso em: 21 dez. 2019.

PERFETTI, J. J. et al. Políticas para el desarrollo de la agricultura en Colombia. Bogotá: SAC; Fedesarrollo, 2013.

PLOEG, J. D. Van der. The peasantries of the twenty-first century: the commoditization debate revisited. Journal of Peasant Studies, [s. 1.], v. 37, n. 1, p. 1-40, 2010.

PNUD. Plataforma Agenda 2030. 2015. Disponível em:

<http://www.agenda2030.org.br/sobre/>. Acesso em: 18 dez. 2019.

RAMOS, Y. L. M. Políticas Públicas para la Agricultura Familiar en Colombia:

Contribuciones y Retos para el Desarrollo Rural. Estudos de Administração e Sociedade, [s. 1.], v. 1, n. 1, p. 42-52, 2016.

SABORIN, E. et al. Análisis transversal de las políticas sobre agricultura familiar en América Latina. In: SABORIN, E.; SAMPER, M.; SOTOMAYOR, O. (Eds.). Políticas públicas y agriculturas familiares en América Latina y el Caribe. Balance, desafíos y perspectivas. Santiago de Chile: CEPAL, 2014. p. 19-48.

SALCEDO, S.; OZ, A. P. De la; GUZMÁN, L. El concepto de agricultura familiar en América Latina y el Caribe. In: SALCEDO, S.; GUZMÁN, L. (Eds.). Agricultura familiar en América Latina y el Caribe. Recomendaciones de política. Santiago de Chile: FAO, 2014. p. 17-33.

SANTOS, J. M.; JIMÉNEZ, T. Acuerdo final para la terminación del conflicto y la construcción de una paz estable y duradera, Presidencia de la República, 2016.

SCHEJTMAN, A.; BERDEGUÉ, J. A. Desarrollo territorial rural: Debates y temas rurales. Santiago de Chile: Rimisp, 2004.

SCHNEIDER, S.; ESCHER, F. La construcción del concepto de agricultura familiar en América Latina. Chile, 2012.

UPRA. Criterios generales para la agricultura familiar, Agriconsulting; Minagricultura, 2015.

VALLE, L. M. La heterogeneidad de las agriculturas familiares en el Ecuador. In:

CRAVIOTTI, C. (Ed.). Agricultura familiar en Latinoamérica. Continuidades, transformaciones y controversias. 1a. ed. Buenos Aires: Fundación Ciccus, 2014. p. 57-79.

WANDERLEY, M. de N. B. Agricultura familiar e campesinato: rupturas e continuidade. Estudos Sociedade e Agricultura, [s. 1.], n. 21, p. 42-62, 2003. 
WIGGINS, S. Can the smallholder model deliver poverty reduction and food security for a rapidly growing population in Àfrica?, FAO, 2009.

WILKINSON, J. Mercados, redes e valores: o novo mundo da agricultura familiar. Porto Alegre: UFRGS, 2008. 